\title{
Assessment of Streamflow Regime Alterations in Tang River, China
}

\author{
Yingshan Sun ${ }^{1,2}$, Qiang $\operatorname{Liu}^{2,3, *}$, Xiaomin Yuan ${ }^{2,3}$, Sirui Yan ${ }^{2,3}$ \\ ${ }^{1}$ School of Water Conservancy and Environment, University of Jinan, Jinan, Shandong, 250022, China \\ ${ }^{2}$ State Key Laboratory of Water Environment Simulation, School of Environment, Beijing Normal University, Beijing, 100875, China \\ ${ }^{3}$ Key Laboratory for Water and Sediment Sciences, Ministry of Education, School of Environment, Beijing Normal University, Beijing, \\ 100875, China
}

\begin{abstract}
The biodiversity and integrity of river ecosystems are depending on the natural streamflow regime. Therefore, assessing alteration of hydrologic regimes becomes a fundamental step in river ecosystem protection and restoration. In this paper, the Range of Variability Approach (RVA) was used to analyze the alteration hydrologic regimes from 1959 to 2016 in the Tang River, the upstream of Baiyangdian Lake Basin, China. Several results can be drawn: $(i)$ annual streamflow presented a decreasing trend, and an abrupt change was detected in 1979; (ii) the significant changed indicators of hydrologic variation in upstream of Baiyangdian Lake Basin were the monthly streamflow in March, April, August, November, time of 3-day and 90-day maximum streamflow, date of maximum streamflow occurrence, rise rate and number of reversals; and (iii) monthly water should be restored in flood and delivered in non-flood season, and annual extreme streamflow frequency and duration of high and low streamflow also should be regulated to maintain the streamflow regimes in the Tang River Basin, China. The results will help to provide the suitable ecological streamflow and maintain the integrity of river ecosystem in changing environment.
\end{abstract}

\section{Introduction}

The biodiversity and integrity of river ecosystems depend on natural streamflow conditions, and can be characterized by ecologically relevant hydrologic indicators of streamflow data ${ }^{[1]}$. However, climate changes combined with human activities (e.g., water diversion, dam construction, and urban development) have changed the natural streamflow of rivers around the world. Alteration of hydrologic regimes are considered to be the main cause of degradation of river ecosystems ${ }^{[2]}$. In this context, to explore the changes of hydrologic regimes and diagnosis alteration of hydrologic indicators have been regarded as one of effective methods to support river management.

Range of Variations method (RVA) was proposed by Richter et $a l .^{[3]}$ which has been widely used to obtain streamflow characteristics in natural and changed conditions ${ }^{[4-7]}$. However, there still remained uncertainty in providing suitable streamflow regime for restoring aquatic ecosystem. Consequently, our objectives are: $(i)$ to explore the temporal trend of streamflow in annual scale; (ii) to obtain the Indicators of Hydrologic Alteration (IHA) parameters with significant changes; and (iii) to propose the suitable ecological streamflow for the river restoration. The results should help to provide the suitable ecological streamflow and maintain the integrity of river ecosystem.

\section{Study sites and data}

Baiyangdian Lake is the largest freshwater lake in northern China ${ }^{[8]}$. Historically, nine rivers flow into the lake. In recent decades, most rivers influenced by the climate changes and human activities have dried up, which has led to degradation of aquatic ecosystem in the Baiyangdian Lake. In order to maintain the integrity of Baiyangdian Lake, several water transfer projects have been conducted to meet the ecological water requirement since 1980s, which have altered the natural hydrologic processes. Especially, planning outline of the national Xiong'an new district, which is intended to optimize regional spatial patterns and enhance ecosystem services and living environment, provide a new goal for the ecological restoration in the Baiyangdian Lake. This study selected Tang River as a study site in the upper reaches of Baiyangdian Lake to explore the alteration of hydrologic regimes using IHA and RVA (Figure 1). The daily hydrologic data were obtained from Zhongtangmei hydrologic station during 1959 and 2016.

\footnotetext{
*Corresponding author's e-mail: liuqiang@bnu.edu.cn
} 


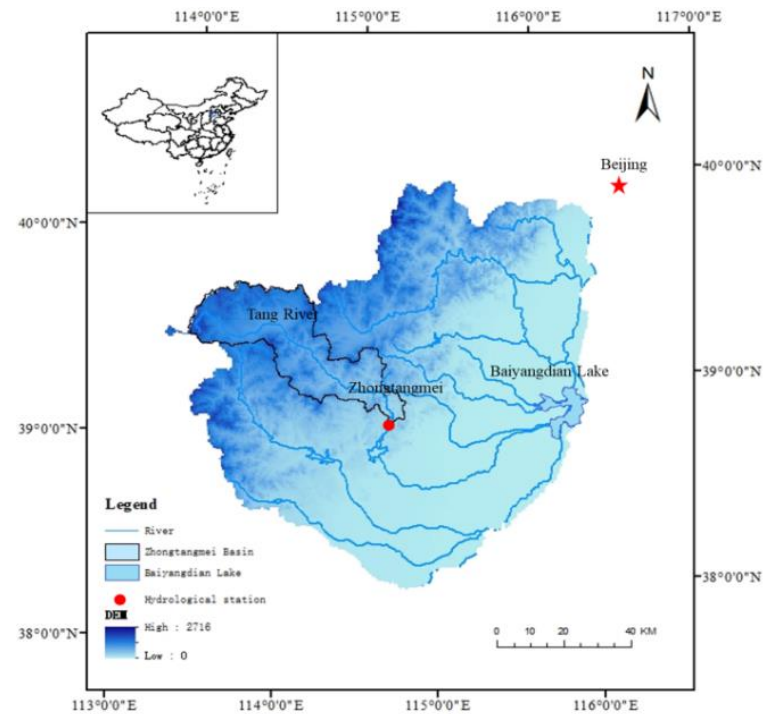

Figure 1. The locations of Tang River Basin and hydrologic station in the Baiyangdian Lake Basin.

\section{Methodology}

\subsection{Temporal trend of streamflow}

Mann-Kendall non-parametric test can be used for abrupt changes testing. For time series $x_{1}, x_{2} \ldots x_{n}$, build order column ${ }^{[9,10] \text { : }}$

$$
S_{k}=\sum_{i=1}^{k} r_{i} \quad(k=2,3 \ldots \ldots n),
$$

when $x_{i}>x_{j}, r_{i}=1$, when $x_{i}<x_{j}, r_{i}=0(\mathrm{j}=1,2, \ldots, \mathrm{i})$.

Under the assumption that the time series is randomly independent, the defined statistics are:

$$
U F_{k}=\frac{\left[s_{k}-\bar{s}_{k}\right]}{\sqrt{\operatorname{Var}\left(S_{k}\right)}} \quad(k=1,2, \ldots \ldots n),
$$

where, $U F_{1}=0, \operatorname{Var}\left(S_{k}\right), \bar{S}_{k}$ are cumulative amount accumulation variance and mean of $S_{k}$, respectively, can be calculated from the following formula:

$$
\begin{aligned}
& \bar{S}_{k}=\frac{n(n-1)}{4}, \\
& \operatorname{Var}\left(S_{k}\right)=\frac{n(n-1)(2 n+5)}{72},
\end{aligned}
$$

where, $U F_{k}$ is in a standard normal distribution, which is a statistical sequence calculated from the time series $x_{1}$, $x_{2}, \ldots x_{n}$, given the significance level 0.05 , the critical value is $U(0.05)= \pm 1.96$.

Create a invert time series $x_{n} \ldots x_{2}, x_{1}$ named $U B_{k}$, repeating the above procedure, $U F_{k}=-U B_{k}(k=n, n-1 \ldots, 1)$, $U B_{I}=0$. If the two curves $U F_{k}$ and $U B_{k}$ intersect, and the intersection is between the critical lines, then the corresponding moment of intersection is the time at which the mutation begins.

\subsection{Indicators of Hydrologic Alteration}

The RVA method proposed by Richter et al. ${ }^{[3]}$ has been widely used to analysing the hydrologic regimes characteristics. In RVA method, IHA are categorized in five groups, as shown in Table $1^{[6,11]}$.

Table 1. Indicators of hydrologic alteration (IHA).

\begin{tabular}{cc}
\hline IHA group & Hydrologic indicators \\
\hline Group 1: Magnitude of monthly water conditions & Mean value for each calendar month \\
1-day minimum & 3-day minimum \\
Group 2: Magnitude and duration of annual extreme water conditions & 7-day minimum \\
& 30-day minimum \\
& 90-day minimum \\
& 1-day maximum \\
Group 3: Timing of annual extreme water conditions & 3-day maximum \\
& 7-day maximum \\
Group 4: Frequency and duration of high and low pulses & 30-day maximum \\
& 90-day maximum \\
& Date of minimum \\
& Date of maximum \\
& Low pulse count \\
Group 5: Rate and frequency of water condition changes & Low pulse duration \\
& High pulse count \\
& High pulse duration \\
& Rise rate \\
& Fall rate \\
\hline
\end{tabular}




\subsection{Range of Variability Approach}

The RVA is based on the IHA, with detailed flow data to determine the state of river streamflow before and after change, in order to analyze the degree of hydrologic change before and after river change. [12].

The definition of hydrologic alteration is as follows

$$
D_{i}=\frac{N_{i}-N_{e}}{N_{e}} \times 100 \%,
$$

where, $D_{i}$ is the degree of change of the $i^{\text {th }}$ hydrometric indicator, $N_{i}$ is the number of years in which the annual total streamflow fall within the target range after the variation of the eco-hydrometric indicator, $N_{e}$ is the expected number of years, $N_{e}=r N_{t}$, where $r$ is the proportion of the pre-interference hydrologic indicators falling within the RVA target, in this study, from $25.00 \%$ to $75.00 \%$ of each hydrologic indicator as the RVA target, then $r$ is $50 \%$, and $N_{t}$ is the number of years of the interference after streamflow observation. To map hydrologic alteration, Richter divided the ranges of hydrologic alteration (0-100.00\%) into three classes of equal range and assigned each class a distinct pattern: $(i)$ $0-33.33 \%$ represents little or no alteration; (ii) $34.00 \%-66.00 \%$ represents moderate alteration; (iii) $67.00 \%-100 \%$ represents a significant alteration.

\section{Results and Discussion}

\subsection{Temporal trends of streamflow}

Annual streamflow presented a significant decreasing trend $(\mathrm{P}<0.05)$ with an average increase of $-0.0059 \times$ $10^{9} \mathrm{~m}^{3} \cdot \mathrm{a}^{-2}$ during 1959 and 2016 (Figure 2a). The results were consistent with Tian et al. ${ }^{[13]}$. According to Mann-Kendall method, the downward abrupt change was detected in 1979 (Figure 2b). The results were consistent with Liu et al. ${ }^{[14]}$. According to timing of abrupt change, annual streamflow can be divided into two periods: natural period (1959-1978) and changed period (1979-2016). The average annual streamflow were 0.37 $\times 10^{9} \mathrm{~m}^{3} \cdot \mathrm{a}^{-1}$ and $0.20 \times 10^{9} \mathrm{~m}^{3} \cdot \mathrm{a}^{-1}$ in the natural and changed period, respectively.

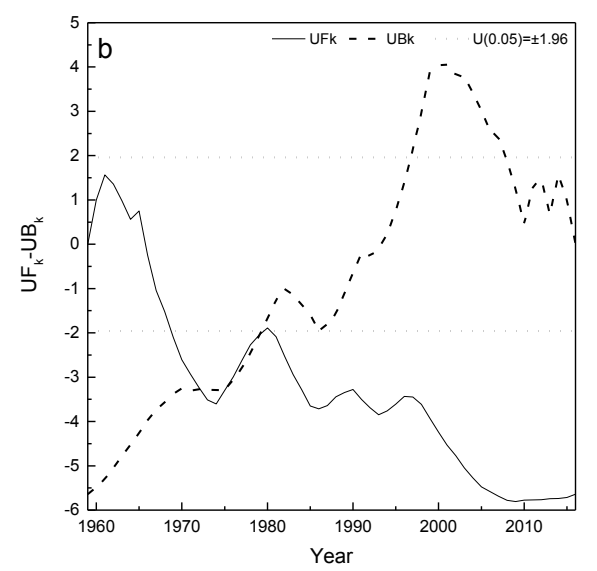

Figure 2. The temporal trend (a) and abrupt change detection using Mann-Kendall method (b).

\subsection{Streamflow regime alteration assessment}

Assessed by hydrologic degree of variation (D), hydrologic parameters altered between natural and changed periods (Table 2). Generally, the greatest variations at monthly scales presented a significant decrease $(|D|>66.00 \%)$ trend in four months: March,
April, August, and November; and $D$ for these four months were $-67.00 \%,-80.00 \%,-87.00 \%$ and $-67.00 \%$, respectively. For count and duration of annual extreme streamflow, 3-day and 90-day maximum streamflow presented significant variation. Values of $D$ for the two parameters were both $-74.00 \%$.

Table 2 IHA alteration and degree of variation for hydrologic Tang River Basin.

\begin{tabular}{|c|c|c|c|c|c|c|c|c|c|c|c|}
\hline & \multicolumn{4}{|c|}{ Natural period: $1959-1978$} & \multicolumn{4}{|c|}{ Changed period: $1979-2016$} & \multicolumn{2}{|c|}{ RVA Boundaries } & \multirow{2}{*}{$\begin{array}{c}\text { Hydrologic } \\
\text { Alteration } \\
(\%)\end{array}$} \\
\hline & Means & Variation & Minimum & Maximum & Means & Variation & Minimum & Maximum & $\begin{array}{c}\text { Low } \\
(25 \%) \\
\end{array}$ & $\begin{array}{c}\text { High } \\
(75 \%) \\
\end{array}$ & \\
\hline January & 4.97 & 0.71 & 2.93 & 10.20 & 3.93 & 0.42 & 0.00 & 7.97 & 4.01 & 6.82 & -1 \\
\hline February & 5.16 & 0.61 & 2.93 & 12.70 & 3.82 & 0.36 & 0.00 & 6.80 & 4.21 & 6.45 & -21 \\
\hline March & 4.97 & 0.64 & 2.36 & 10.80 & 3.32 & 0.63 & 0.00 & 5.55 & 4.34 & 6.49 & -67 \\
\hline April & 4.19 & 0.82 & 0.93 & 11.20 & 0.98 & 2.11 & 0.00 & 4.60 & 3.00 & 5.36 & -80 \\
\hline May & 1.71 & 1.35 & 0.25 & 7.62 & 0.87 & 1.58 & 0.00 & 3.58 & 1.19 & 2.81 & -8 \\
\hline June & 2.16 & 1.41 & 0.55 & 7.89 & 0.79 & 1.35 & 0.17 & 10.35 & 1.43 & 3.06 & -61 \\
\hline July & 10.56 & 1.09 & 0.40 & 47.90 & 4.21 & 1.58 & 0.37 & 28.00 & 7.56 & 12.92 & -54 \\
\hline
\end{tabular}




\begin{tabular}{|c|c|c|c|c|c|c|c|c|c|c|c|}
\hline August & 24.05 & 1.02 & 2.70 & 144.00 & 8.14 & 1.35 & 0.71 & 135 & 16.49 & 27.56 & -87 \\
\hline September & 11.13 & 1.02 & 1.61 & 46.30 & 7.06 & 0.73 & 1.82 & 30.00 & 8.79 & 15.79 & -41 \\
\hline October & 8.98 & 0.71 & 1.21 & 24.70 & 5.53 & 0.60 & 0.00 & 14.70 & 6.31 & 12.31 & -28 \\
\hline November & 7.19 & 0.66 & 1.61 & 18.20 & 3.30 & 0.85 & 0.00 & 6.73 & 5.50 & 8.42 & -67 \\
\hline December & 5.37 & 0.63 & 2.12 & 13.90 & 4.48 & 0.37 & 0.00 & 8.69 & 4.54 & 7.58 & -1 \\
\hline $\begin{array}{l}\text { 1-day } \\
\text { minimum }\end{array}$ & 0.60 & 3.17 & 0.08 & 2.90 & 0.21 & 2.19 & 0.00 & 1.55 & 0.20 & 1.12 & 12 \\
\hline $\begin{array}{c}\text { 3-day } \\
\text { minimum }\end{array}$ & 0.75 & 2.76 & 0.10 & 3.56 & 0.21 & 2.23 & 0.00 & 1.67 & 0.23 & 1.21 & -1 \\
\hline $\begin{array}{l}\text { 7-day } \\
\text { minimum }\end{array}$ & 1.09 & 1.95 & 0.11 & 4.71 & 0.26 & 1.80 & 0.00 & 1.89 & 0.44 & 1.59 & -8 \\
\hline $\begin{array}{l}\text { 30-day } \\
\text { minimum }\end{array}$ & 1.76 & 1.26 & 0.24 & 6.45 & 0.47 & 1.86 & 0.00 & 2.47 & 0.84 & 2.53 & -21 \\
\hline $\begin{array}{l}\text { 90-day } \\
\text { minimum }\end{array}$ & 2.55 & 1.20 & 0.81 & 7.12 & 1.02 & 1.28 & 0.00 & 3.13 & 1.94 & 3.55 & -47 \\
\hline $\begin{array}{c}\text { 1-day } \\
\text { maximum }\end{array}$ & 127.50 & 2.07 & 8.83 & 3350 & 52.40 & 2.52 & 5.46 & 720 & 97.35 & 177.10 & -34 \\
\hline $\begin{array}{l}\text { 3-day } \\
\text { maximum }\end{array}$ & 93.55 & 1.55 & 5.83 & 2191 & 40.61 & 2.17 & 4.57 & 516 & 67.45 & 123.80 & -74 \\
\hline $\begin{array}{l}\text { 7-day } \\
\text { maximum }\end{array}$ & 59.71 & 1.81 & 5.34 & 1099 & 27.39 & 2.31 & 4.06 & 387.10 & 50.99 & 89.35 & -54 \\
\hline $\begin{array}{l}\text { 30-day } \\
\text { maximum }\end{array}$ & 34.38 & 1.57 & 4.66 & 294.90 & 15.58 & 1.54 & 3.52 & 174.90 & 26.20 & 68.70 & -54 \\
\hline $\begin{array}{l}\text { 90-day } \\
\text { maximum }\end{array}$ & 22.14 & 1.36 & 4.18 & 108.80 & 9.93 & 1.15 & 3.15 & 73.69 & 17.79 & 36.67 & -74 \\
\hline $\begin{array}{l}\text { Number of } \\
\text { zero days }\end{array}$ & 0.00 & 0.00 & 0.00 & 0.00 & 0.00 & 0.00 & 0.00 & 243.00 & 0.00 & 0.00 & -8 \\
\hline $\begin{array}{l}\text { Base flow } \\
\text { index }\end{array}$ & 0.10 & 2.02 & 0.01 & 0.41 & 0.07 & 1.87 & 0.00 & 0.36 & 0.04 & 0.18 & 18 \\
\hline $\begin{array}{l}\text { Date of } \\
\text { minimum }\end{array}$ & 177 & 0.08 & 122 & 187 & 147 & 0.15 & 1.00 & 275 & 174 & 179.10 & -77 \\
\hline $\begin{array}{l}\text { Date of } \\
\text { maximum }\end{array}$ & 217.50 & 0.06 & 188 & 241 & 217.50 & 0.06 & 163 & 253 & 211 & 226.10 & 12 \\
\hline $\begin{array}{l}\text { Low pulse } \\
\text { count }\end{array}$ & 8.00 & 0.88 & 1.00 & 20 & 6.00 & 0.54 & 1.00 & 14.00 & 4.93 & 11.00 & 29 \\
\hline $\begin{array}{l}\text { Low pulse } \\
\text { duration }\end{array}$ & 4.00 & 1.06 & 2.00 & 18 & 12.00 & 1.26 & 2.00 & 114 & 3.00 & 6.04 & -47 \\
\hline $\begin{array}{l}\text { High pulse } \\
\text { count }\end{array}$ & 5.00 & 0.60 & 0.00 & 11 & 3.00 & 0.67 & 0.00 & 11.00 & 4.00 & 7.00 & -65 \\
\hline $\begin{array}{l}\text { High pulse } \\
\text { duration }\end{array}$ & 4.00 & 0.63 & 1.00 & 14.50 & 4.00 & 2.19 & 1.00 & 54.50 & 3.00 & 4.00 & -42 \\
\hline Rise rate & 0.56 & 0.57 & 0.24 & 1.70 & 0.26 & 1.44 & 0.03 & 3.67 & 0.50 & 0.64 & -74 \\
\hline Fall rate & -0.59 & -0.53 & -1.80 & -0.30 & -0.36 & -0.97 & -2.20 & -0.07 & -0.67 & -0.48 & -61 \\
\hline $\begin{array}{c}\text { Number of } \\
\text { reversals }\end{array}$ & 102.00 & 0.16 & 76 & 130 & 48.00 & 1.06 & 20.00 & 124 & 94.93 & 107.10 & -67 \\
\hline
\end{tabular}

\subsection{Analysis of hydrologic alteration detected by RVA}

\section{(1) Monthly streamflow variation}

For monthly streamflow, variations in flood (e.g., April) and non-flood (e.g. August) seasons were presented in Figure 3. For April, average streamflow are $0.14 \times 10^{9} \mathrm{~m}^{3}$ and $0.040 \times 10^{9} \mathrm{~m}^{3}$ in natural and changed streamflow in $40.00 \%$ years $(8 / 20)$ and $10.52 \%(4 / 38)$ years reached to suitable ecological streamflow in the natural and changed periods, respectively. For August, average streamflow are $0.23 \times 10^{9} \mathrm{~m}^{3}$ and $0.13 \times 10^{9} \mathrm{~m}^{3}$ in natural and changed periods, respectively; streamflow in $40.00 \%$ years $(8 / 20)$ and $7.89 \%$ (3/38) years reached to suitable ecological streamflow in the natural and changed periods, respectively. 

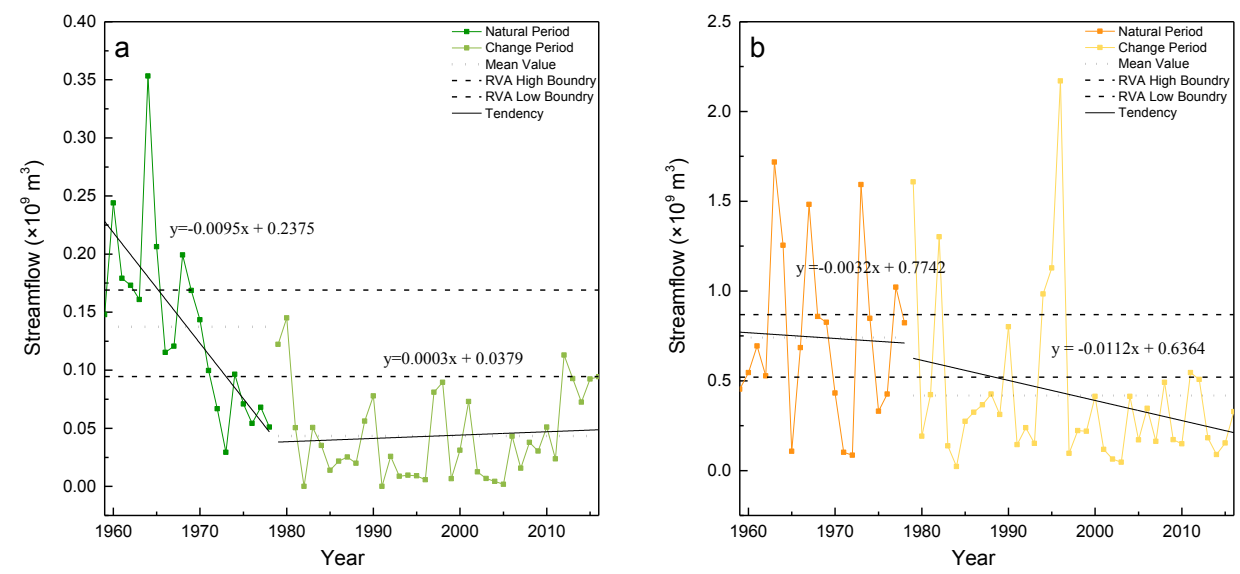

Figure 3. Variation of monthly streamflow during natural and changed period (a. April; b. August).

(2) Annual extreme streamflow occurrence

The Julian date of annual minimum and maximum streamflow was slightly earlier in changed period than that in natural period (Figure 4). A small difference existed in $D$ variation between natural and changed

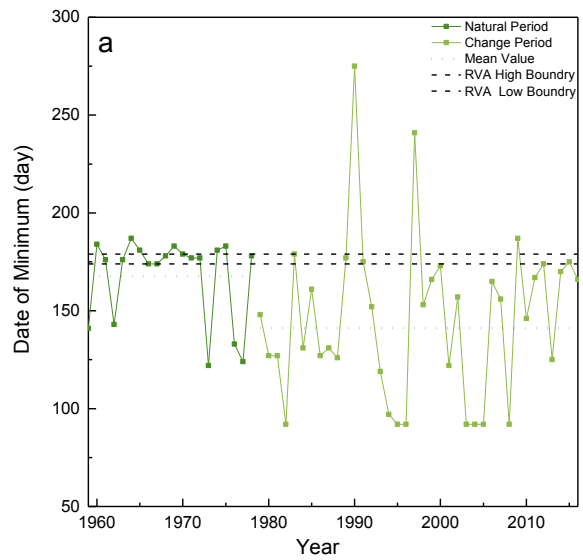

periods, with $D$ value ranging from $-77.00 \%$ to $12.00 \%$, respectively. The date for 1-day minimum streamflow and 1-day maximum streamflow were earlier in the changed period than that in natural period.

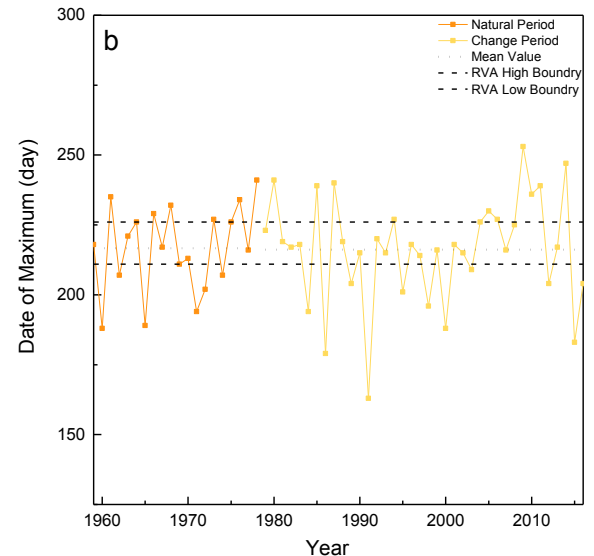

Figure 4. The onset date for maximum and minimum streamflow in Tang River Basin during natural and changed periods (a. date of minimum, b. date of maximum).

(3) Frequency and duration of high and low streamflow

The counts of high and low pulses were reduced by $25.00 \%$ and $40.00 \%$, respectively. The $D$ for the count of high and low pulses presented moderate changes $(33.00 \%$ $<|D|<66.00 \%$ ) compared with the natural periods. The high pulse duration $D$ was $-42.00 \%$, while the low pulse duration increased $(|D|=47.00 \%<66.00 \%)$, increased from 4 days in natural period to 12 days in changed period. The average count of high pulses (showed in Figure 5) decreased from 5 times in the natural period to 3 times in the changed period. While the count of low pulses in the natural and changed periods were 8 times and 6 times, respectively. The decrease of high and low pulse counts will lead to the disappearance of some low-flow channels, and the nutrients carried by rivers are not easily absorbed by aquatic organisms and surrounding vegetation. 

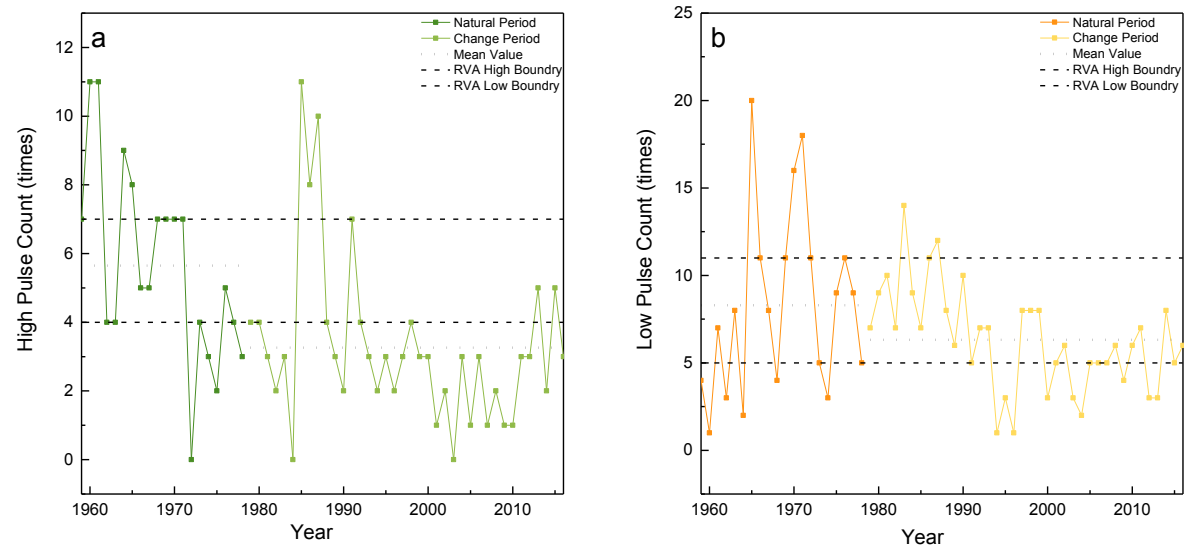

Figure 5. Changes of frequency of high and low pulses for hydrologic data series during natural and changed periods (a. high pulse count, b. low pulse count).

\section{Conclusion}

Alteration of hydrologic regimes has dramatically influenced integrity of aquatic ecosystem. In present study, alterations of hydrologic processes were analyzed. Several conclusions can be drawn:

(i) The annual streamflow presented a decreasing trend of $0.0059 \times 10^{9} \mathrm{~m}^{3} \cdot \mathrm{a}^{-2}$ during 1959-2016, and a decreasing abrupt change was detected in 1979, which was used to split hydrologic series into natural and changed periods.

(ii) According to IHA and RVA, the significant alteration of hydrologic indicators were the average streamflow in March, April, August and November, the maximum streamflow time of 3-day and 90-day series, date of maximum streamflow occurrence, rise rate, and number of reversals.

And (iii) according to RVA monthly streamflow results, significant alteration of hydrologic indicator showed monthly streamflow in non-flood season should be from $0.054 \times 10^{9} \mathrm{~m}^{3}$ to $0.28 \times 10^{9} \mathrm{~m}^{3}$, while monthly streamflow in flood season should be ranged from $0.068 \times 10^{9} \mathrm{~m}^{3}$ to $0.76 \times 10^{9} \mathrm{~m}^{3}$. Furthermore, annual extreme streamflow, and frequency and duration of high and low streamflow also should be regulated to maintain the streamflow regimes in the Tang River Basin, China.

\section{Acknowledgement}

This study was supported by the National Natural Science Foundation of China (No. 51439001, 51579008), and the Major Science and Technology Program for Water Pollution Control and Treatment (2018ZX07110001). The authors of this study would like to thank Baoding Hydrological and Water Resources Survey Bureau for providing the hydrological data.

\section{References:}

1. Jiang, L., Ban, X., Wang, X., Cai, X.J.W.. (2014) Alterations Caused by the Three Gorges Dam in the
Middle and Lower Reaches of Yangtze River, China. Assessment of Hydrologic, 6(5): 1419-34.

2. Poff, L. R., Allan, J. D., Bain, M. B., Karr, J. R., Prestegaard, K. L., Richter, B. D.. (1997) The natural flow regime. Bioscience, 47(11), 769-784.

3. Zhang, Q., Xu, C.Y., Chen, Y.D., Yang, T.. (2010) Spatial assessment of hydrologic alteration across the pearl river delta, china, and possible underlying causes. Hydrological Processes, 23(11), 1565-1574.

4. Chen, Y.D., Tao, Y., Xu, C.Y., Qiang, Z., Xi, C., Hao, Z.C.. (2010) Hydrologic alteration along the middle and upper east river (dongjiang) basin, south china: a visually enhanced mining on the results of rva method. Stochastic Environmental Research \& Risk Assessment, 24(1), 9-18.

5. Richter, B.D., Baumgartner, J.V., Powell, J., Braun, D.P.. (2010) A method for assessing hydrologic alteration within ecosystems. Conservation Biology, 10(4), 1163-1174.

6. Richter, B., Baumgartner, J., Wigington, R., Braun, D.. (1997) How much water does a river need? Freshwater Biology, 37(1), 231-249.

7. Yu, C., Xin'an Yin, Yang, Z.. (2016) A revised range of variability approach for the comprehensive assessment of the alteration of flow regime. Ecological Engineering, 96, 200-207.

8. Zhuang, C., Ouyang, Z., Xu, W., Bai, Y., Zhou, W., Zheng, H., et al. (2011) Impacts of human activities on the hydrology of baiyangdian lake, china. Environmental Earth Sciences, 62(7), 1343-1350.

9. Liang, L., Li, L., Liu, Q.. (2011) Precipitation variability in northeast china from 1961 to 2008. Journal of Hydrology, 404(1-2), 67-76.

10. Akwei, E., Lu, B.H. , Zhang, H.W.. (2013) precipitation trend analysis by mann-kendall test: a case of tianchang county anhui province, china. Advanced Materials Research, 864-867, 2218-2223.

11. conditions in hanjiang river, china. Ecological Engineering, 81, 41-52.

12. Shiau, J.T.A., Wu, F.C.B.. (2010) A histogram matching approach for assessment of flow regime alteration: application to environmental flow optimization. River Research \& Applications, 24(7), 914-928. 
13. Tian F, Han SM, Hu YK. Variance trendency of precipitation and runoff in mountain watershed of Hai River Basin in rencent 34 yeas. [J]. 2009, 30(1): 60-5.

14. Liu MF, Gao YC,Gan GJ. Long-Term Trends in Annual Runoff and the Impact of Meteorological Factors in the Baiyangdian Watershed [J]. 2011, 33(8): 1438-45. 